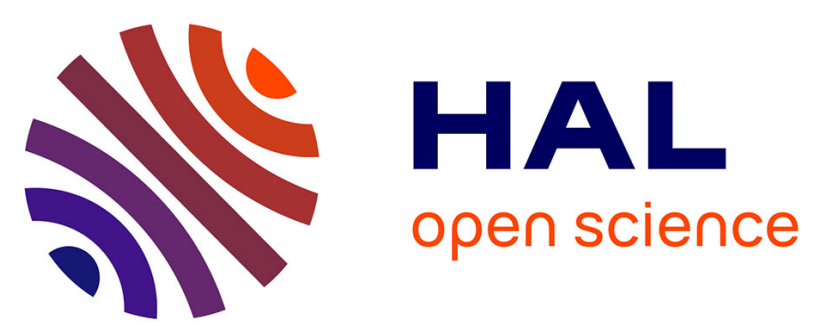

\title{
Disc Motor with Rotor Made of Aluminium or Polycrystalline High Temperature Superconductor
}

David Inácio, João Murta Pina, Mário Ventim Neves, Alfredo Álvarez

\section{To cite this version:}

David Inácio, João Murta Pina, Mário Ventim Neves, Alfredo Álvarez. Disc Motor with Rotor Made of Aluminium or Polycrystalline High Temperature Superconductor. 6th Doctoral Conference on Computing, Electrical and Industrial Systems (DoCEIS), Apr 2015, Costa de Caparica, Portugal. pp.451-458, 10.1007/978-3-319-16766-4_48 . hal-01343515

\section{HAL Id: hal-01343515 \\ https://hal.inria.fr/hal-01343515}

Submitted on 8 Jul 2016

HAL is a multi-disciplinary open access archive for the deposit and dissemination of scientific research documents, whether they are published or not. The documents may come from teaching and research institutions in France or abroad, or from public or private research centers.
L'archive ouverte pluridisciplinaire HAL, est destinée au dépôt et à la diffusion de documents scientifiques de niveau recherche, publiés ou non, émanant des établissements d'enseignement et de recherche français ou étrangers, des laboratoires publics ou privés. 


\title{
Disc Motor with Rotor Made of Aluminium or Polycrystalline High Temperature Superconductor
}

\author{
David Inácio ${ }^{1}$, João Murta Pina ${ }^{1}$, Mário Ventim Neves ${ }^{1}$, Alfredo Álvarez ${ }^{2}$ \\ ${ }^{1}$ CTS, Uninova, Departamento de Engenharia Electrotécnica, Faculdade de Ciências e \\ Tecnologia, FCT, Universidade Nova de Lisboa, 2829-516 Caparica, Portugal \\ ${ }^{2}$ Departament of Electrical Engineering, Escuela de Ingenierias Industriales, Universidad de \\ Extremadura, E-06006 Badajoz, Spain
}

\begin{abstract}
The discovery of the superconductivity and the understanding of electromagnetic properties of high temperature superconducting (HTS) materials allowed the optimization and development of several applications, such as electrical machines and drives. Electromechanical conversion devices based in HTS materials potentially allows for reduction in devices dimensions or performance improvement for the same active volume, when compared with their conventional ones.An axial disc motor with high temperature superconductor (HTS) material or conventional aluminium in the rotor and conventional armature has been designed and developed. This paper describes simulations and laboratory experiments performed at liquid nitrogen temperature $(77 \mathrm{~K})$ in order to analyze the motor's behaviour and its electromechanical characteristics and to define an electric equivalent circuit that allows describing its operation. From the obtained results it was observed that the tested HTS behaves as a conventional hysteresis motor even though with a different nature. On the other hand, the motor with aluminium rotor behaves as a conventional induction motor. In asynchronous regime, the HTS motor exhibits a constant torque, higher than the conventional aluminium one.
\end{abstract}

Keywords: High temperature superconducting motor, polycrystalline YBCO, axial flux disc motor.

\section{Introduction}

In 1911, Kamerling Onnes found a new state of matter in mercury, which exhibited electric resistance when cooled bellow 4.2 K. This was named Superconductivity [1]. The interest in these materials was accentuated by the discovery of High Temperature Superconductors (HTS) possible to cool by relatively cheap liquid nitrogen (77 K). Research on these materials have lead to the optimization and development of several power systems. HTS material have been used e.g. in machines, both as tapes or bulk. The HTS YBCO compound (with a current density up to $10^{7} \mathrm{~A} \cdot \mathrm{cm}^{-2}$ at liquid nitrogen temperature) has been applied in electrical machines, such as hysteresis [2], reluctance [3], or trapped flux motors [4]. The former present a complex behaviour, 
showing both synchronous and asynchronous regimes, similar to hysteresis conventional motors, although the operation principle is different [2]. The ability of trapping high magnetic flux, transporting high current densities, and its diamagnetism phenomena and hysteretic ability made HTS materials attractive, presenting reduced size and losses, for the same power, relatively to its conventional counterpart [5]. This lead to the research question "does polycrystalline HTS hysteresis motors show better electromagnetic characteristics than aluminium ones?".

\section{Relationship to Cloud-based Solutions}

The study of an axial flux disc motor with the rotor in HTS polycrystalline material or aluminium, for several poles pairs configurations is preformed in this paper. All the obtained results could be shared in a cloud-based system allowing other researchers to perform analysis, and providing data backup an on-time data monitoring.

\section{Developed Motor}

Typically, the output power of rotating machine, $P_{\text {out }}$, may be expressed according to (1) [7], where $B_{g, \max }$ is the maximum airgap flux density, $A_{g, \max }$ is the maximum stator linear current, $N_{m e c}$ is the rotor speed and $V$ is the active volume. The use of superconducting materials allows a higher flux density in the airgap, increasing the developed power.

$$
P_{\text {out }} \propto B_{g, \max } \cdot A_{s, \max } \cdot N_{\text {mec }} \cdot V
$$

\subsection{Topology}

The built disc motor, is composed by two $20 \mathrm{~cm}$ diameter conventional semi-stators with 24 slots, a coil pitch of 4 slots, 24 conventional cooper windings each one, a steel shaft, a $20 \mathrm{~cm}$ diameter rotor disc, which can be aluminium or YBCO, two support bearings and fixing screws. The mechanical transmission is carried by conventional bearings dryed by ultrasounds. Further details are given in [8].

\subsection{Electromagnetic Characteristics}

When stator is energized, it produces rotating magnetic field. This field magnetizes the rotor. For the aluminium rotor, the behaviour is known. For the HTS rotor, the field magnetizes the HTS material, which is penetrated with magnetic flux that is trapped in the pinning centres, inducing the same stator's poles number. Due to this, the superconductors' rotor rotates synchronous with stator field, acting as a magnet. 
For load values lower than the maximum motor's torque, it runs with synchronous velocity. In steady state, there is a constant relative angle between the stator's and the rotor's magnetic field, which origins a constant motor torque proportional to the product of the amplitudes of two fields with the phase between them. For values of load higher than the maximum motor's torque, flux flow is present, and the motor runs with slip. The torque is proportional to the HTS materials losses.

\subsection{Simulations}

The motor was simulated with a commercial 2D finite elements program (Flux2D from Cedrat). The 2D limitation implied the simulation of a linearized version of the motor, considering longitudinal infinite continuous periodicity to avoid edge effects. All the non-HTS materials, (copper, aluminium and steel) were defined using Flux2D libraries. The HTS material was parameterized based in the E-J power law, with the parameters indicated in Table 1. HTS motor was analysed for 1, 2 and 4 pole pairs.

Table 1. Measured and predicted electrical parameters from experimental tests.

\begin{tabular}{ccc}
\hline Critical Electrical Field & $E_{\mathrm{c}}$ & $10^{-4} \mathrm{~V} \cdot \mathrm{m}^{-1}$ \\
Critical Current Density & $J_{\mathrm{c} 0}$ & $4,4 \times 10^{7} \mathrm{~A} \cdot \mathrm{m}^{-2}$ \\
Induction & $B_{0}=B_{1}$ & $10^{6} \mathrm{~T}$ \\
Exponent & $n$ & 15 \\
Additional Resistivity & $\rho_{0}$ & $10^{-13} \Omega \cdot \mathrm{m}^{-1}$ \\
\hline
\end{tabular}

Transient dynamic simulations were performed. Motor startup is shown in Fig. 1 a), and force dependence on imposed velocity in Fig. 1 b), for no load conditions. From Fig. $1 \mathrm{a}$ ), it is possible to confirm that the motor with aluminium rotor exhibits an asynchronous behaviour while the motor with YBCO rotor presents synchronous behaviour. From Fig. 1 b) it is possible to conclude that both motor's developed a linear force proportional to the pole pairs, being higher for the YBCO motor, when compared with the aluminium. In YBCO motor, for synchronous speed the linear force tends to zero, due to the no-load assumed conditions.
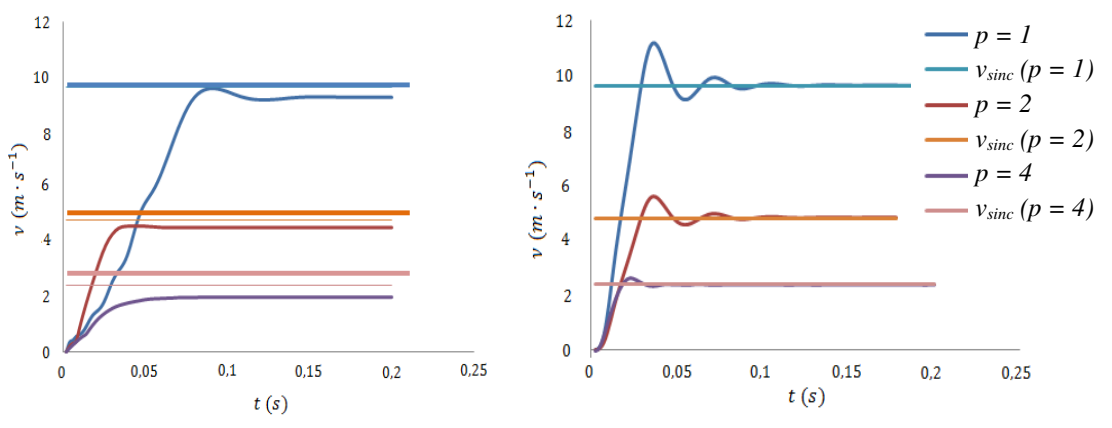

a) Time evolution of the linear velocity. 

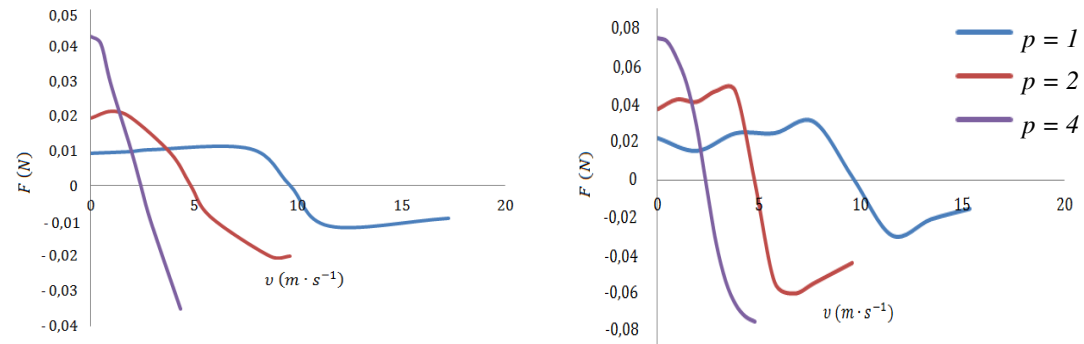

b) Static characteristic of linear force VS imposed linear velocity.

Fig.1. Obtained FEM simulations for a) transitory dynamic and b) permanent regime conditions, for 1, 2 and 4 poles pairs in linear HTS and Aluminium motor, no load conditions.

\subsection{Experimental Tests}

In order to develop a model for the motor blocked-rotor, no-load and load tests were performed for aluminium motor while for the HTS rotor only blocked-rotor and load tests were performed, as this is a synchronous motor. The experimental apparatus consisted in a 3-phase power transformer; electrical and mechanical power measuring modules; and a DC machine, load cells and optical sensors for mechanical torque and speed measurements using the mechanical power module. During tests only the disc motor was immersed in liquid nitrogen inside a styrofoam box. All the apparatus are shown in Fig. 2.

The motor was supplied by a wye connected $23 \mathrm{~V}, 50 \mathrm{~Hz}$ source for 1,2 and 4 pair poles configuration. The mechanical load was based in a DC generator (controlled by two DC power supplies and a control resistor) driven by the motors' shaft and feeding a resistive load.

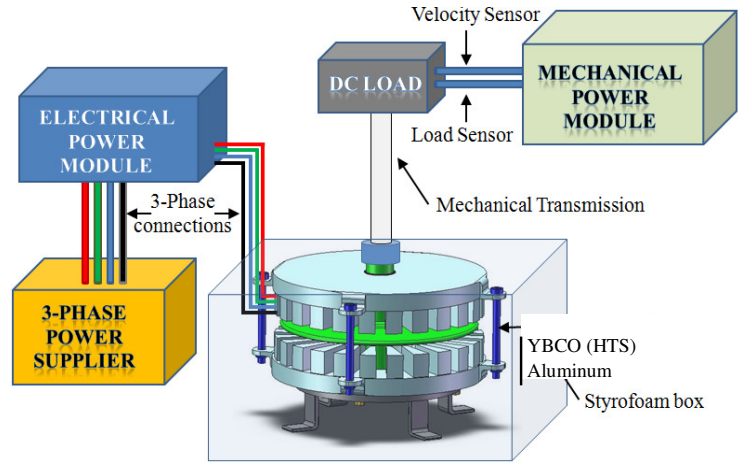

Fig.2. Experimental apparatus for axial flux disc motor's tests. 
The classic equivalent electrical circuit of the motor with aluminium rotor is shown in Fig. 3. From [9], the HTS rotor's motor can be described using the equivalent electrical circuit present in Fig. 3, where $r_{s}, r_{r}$ and $r_{f e}$ are the semi-stator's winding, the rotor's equivalent and the equivalent iron losses resistances while $X_{s}, X_{r}$ and $X_{m}$ are the semi-stator's, equivalent rotor's and magnetizing reactance's. 1

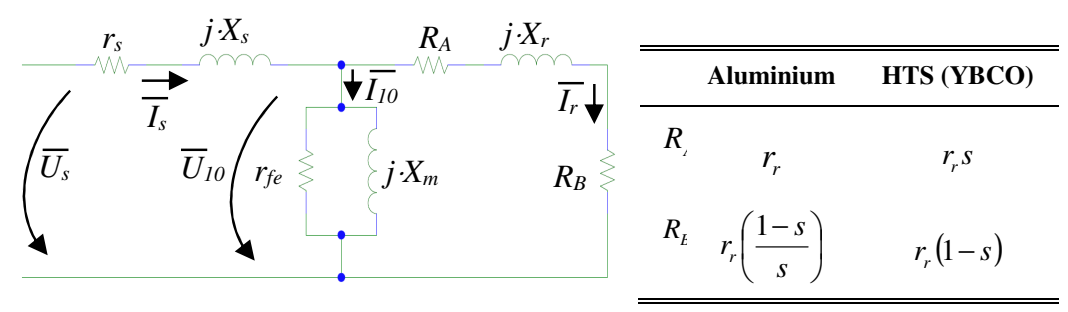

Fig.3. Equivalent circuit for Aluminium motor and HTS (YBCO) polycrystalline bulk motor.

Results from the blocked-rotor, no-load and load tests of the aluminium rotor (line current, $I$, line tension, $U_{c}$, the 3-phase electric power supplied, $\mathrm{P}_{\text {ele }}$, the measured torque, $T$, and the mechanical rotor's velocity, $N$,) were used to determine the parameters of the equivalent electrical circuit, and are synthesized in Table 2.

Concerning the HTS motor, parameters derivation was based in the parameters of aluminium motor since the HTS motor has the same semi-stators and supply system. The value of the magnetic losses, $r_{f e}$, was calculated based upon a similar induction motor case and considered the same for the both cases.

Table 2. Measured and predicted electrical parameters from experimental tests.

\begin{tabular}{cccccc}
\hline Parameter & \multicolumn{3}{c}{ Aluminium } & \multicolumn{2}{c}{ YBCO $(\mathrm{HTS})$} \\
\hline Polar Configuration & 2 & 4 & 8 & 2 & 4 \\
$r_{s}[\Omega]$ & 0.25 & 0.25 & 0.25 & 0.25 & 0.25 \\
$X_{s}[\Omega]$ & 0.317 & 0.346 & 0.325 & 0.317 & 0.346 \\
$X_{r}[\Omega]$ & 0.317 & 0.346 & 0.325 & 0.348 & 0.004 \\
$r_{r}[\Omega]$ & 0.038 & 0.045 & 0.039 & 0.371 & 0.134 \\
$r_{f e}[\Omega]$ & 40.2 & 41.7 & 46.1 & 40.2 & 41.7 \\
$X_{m}[\Omega]$ & 52.79 & 12.95 & 3.26 & 52.02 & 13.01 \\
$\mu_{r}$ & -- & -- & -- & 0.0098 & 0.0103 \\
$\delta$ & -- & -- & -- & 46.85 & 88.29 \\
\hline
\end{tabular}

The theoretical analysis of the HTS motor, allowed defining the magnetization reactance, $X_{m}$, rotor's resistance, $r_{r}$, and rotor's dispersion reactance, $X_{r}$, as indicated in (3) - (5). The parameters used in (3) - (5) are detailed in Table 3. 


$$
\begin{gathered}
X_{m}=\frac{\left(k_{w} \cdot N_{p h}\right)^{2} \cdot \omega \cdot m \cdot\left(r_{o}^{2}-r_{i}^{2}\right) \cdot \mu_{0}}{l_{g} \cdot \pi \cdot p^{2}} \\
r_{r}=\frac{2 \cdot\left(k_{w} \cdot N_{p h}\right)^{2} \cdot \omega \cdot m \cdot\left(r_{o}^{2}-r_{i}^{2}\right) \cdot \mu_{0} \cdot \mu_{r}}{t_{r} \cdot \pi \cdot p^{2}} \sin (\delta) \\
X_{r}=\frac{2 \cdot\left(k_{w} \cdot N_{p h}\right)^{2} \cdot \omega \cdot m \cdot\left(r_{o}^{2}-r_{i}^{2}\right) \cdot \mu_{0} \cdot \mu_{r}}{t_{r} \cdot \pi \cdot p^{2}} \cos (\delta)
\end{gathered}
$$

The analysis of equivalent circuit present in Fig. 3, allows conclude that the input impedance, $\bar{Z}_{i n}$, is given in (6), being $\bar{Z}_{s}$ the stator's impedance, $\bar{Z}_{T}$ the transversal impedance and $\bar{Z}_{r}$ the rotor's impedance.

$$
\bar{Z}_{\text {in }}=\bar{Z}_{s}+\bar{Z}_{T} / / \bar{Z}_{r},\left\{\begin{array}{c}
\bar{Z}_{s}=r_{s}+j X_{s} \\
\bar{Z}_{T}=r_{f e} / / j X_{m} \\
\bar{Z}_{r}=\left(r_{r} \cdot s+(1-s) \cdot r_{r}\right)+j X_{r}
\end{array}\right.
$$

From the blocked rotor test, it's possible to obtain $\bar{Z}_{\text {in }}$. Solving (5) in order to $\bar{Z}_{r}$ it's possible to obtain the values of $\mu_{r}$ and $\delta$, which are present in Table 1 . Using the values indicated in Table 3 and equations (3) - (5) it's possible to predict the values of $X_{m}, r_{r}$, and $X_{r}$. They are indicated in Table 2 for 2 and 4 poles. As is possible to observe, the impedance is inversely proportional to the square of the number of pair poles. For 8 poles the current "asked" to the power supply exceeds the maximum available $(25 \mathrm{~A})$. For that reason, we only perform the experimental tests for 2 and 4 poles.

Table 3. Parameters of axial flux disc motor.

\begin{tabular}{lccc}
\hline \multicolumn{1}{c}{ Parameter } & & Value & Units \\
\hline Outer rotor's radius & $r_{o}$ & 100 & $\mathrm{~mm}$ \\
Inner rotor's radius & $r_{i}$ & 10 & $\mathrm{~mm}$ \\
Airgap & $l_{g}$ & 5 & $\mathrm{~mm}$ \\
Rotor's thickness & $t_{r}$ & 10 & $\mathrm{~mm}$ \\
Winding factor & $k_{w}$ & 0.5 & - \\
Number of turns, per phase & $N_{p h}$ & 528 & turns \\
Frequency & $f$ & 50 & $\mathrm{~Hz}$ \\
Number of phases & $m$ & 3 & - \\
\hline
\end{tabular}

The theoretical electromechanical characteristics were computed, based on the experimentally obtained parameters and using the theoretical analysis above described, and compared with the experimentally obtained characteristics in tests. In Fig. 4 is shoed the comparison between the torque produced in the aluminium rotor's motor and YBCO rotor's motor. As is possible to observe, the experimental characteristics tend to evolutes coherent with the theoretically predicted ones. 
Comparing with the simulated results, it's possible to conclude that the studied motor behaves as expected, however with lower values of torque. It is also important refer that the predicted quantities are related with the torque electrodynamically developed, or internal power, while the measured ones refer to the available quantities in the motor's shaft, which differ from the first ones by the mechanical losses. The main mechanical losses are the viscosity friction in the liquid nitrogen and the friction in the conventional bearings working at low temperature that should be included in the theoretical prediction.

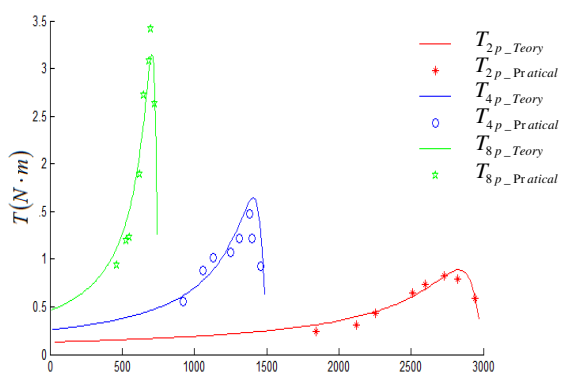

$\Omega_{\text {mec }}(R P M)$

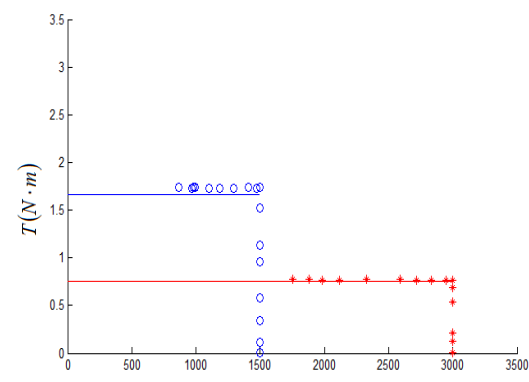

$\Omega_{m e c}(R P M)$

Fig.4. Comparison between theoretical and experimental developed torque for aluminium rotor's motor (left side) and YBCO rotor's motor (right side).

\section{Conclusions}

Flux2D simulations allowed confirming that, for different configurations of poles, the HTS motor exhibits a synchronous behaviour in steady state and the developed force increase with the poles pair, inversely to synchronous speed.

The comparison of simulated, experimental and theoretical results allows conclude that all the characteristics are consistent each them, being possible to observe both synchronous and asynchronous regimes of the HTS motor. The comparison of the developed torques between the aluminium and HTS rotors showed that even for insufficient operating conditions, due to current supply limitation, the motor in bipolar configuration with the HTS rotor a has a higher torque developed compared with the aluminium one. Nevertheless, in tetrapolar configuration, the developed torque in the former is lower when compared to the conventional motor.

Acknowledgments. The authors thank to CTS - UNINOVA and FCT (CTS multiannual funding - PIDDAC Program funds) for the financial support for the work. 


\section{References}

[1] Kamerlingh-Onnes: The Superconductivity of Mercury, Comm. Phys., Lab. Univ. Leiden, Nos. 122 and 124 (1911)

[2] Barnes, G.J., Dew-Hughes, D., McCulloch, M.D.: Finite difference modelling of bulk high temperature superconducting cylindrical hysteresis machines, IOP Science: Superconductor Science and Technology, vol. 13, p.p. 229 (2000)

[3] Kovalev, L.K., Ilushin, K.V., Kovalev, K.L., Penkin, V.T., Poltavets, V.N. Koneev, S.M.-A., et al.: High output power electric motors with bulk HTS elements, Physica C: Superconductivity, vol. 386, pp. 419--423 (2003)

[4] Miki, M., Felder, B., Tsuzuki, K., Deng, Z., Shinohara, N., Izumi, M., et al.: Influence of AC Magnetic Field on a Rotating Machine With Gd-Bulk HTS Field-Pole Magnets, Applied Superconductivity, IEEE Transactions on , vol.21, no.3, pp.1185--1189 (2011)

[5] Inácio, D., Pina, J., Gonçalves, A., Ventim-Neves, M., Rodrigues, A.L.: Numerical and Experimental Comparison of Electromechanical Properties and Efficiency of HTS and Ferromagnetic Hysteresis Motors, 8th European Conference on Applied Superconductivity (EUCAS'07), Belgium, (2007)

[6] Tinkham, M.: Introduction to Superconductivity, McGraw-Hill (1996)

[7] Vajda, I., Szalay, A., Gobl, N., Meerovich, V., Sokolovsky, V.: Requirements for the industrial application of superconducting rotating electrical machines, IEEE Transactions on Applied Superconductivity, vol. 9, issue 2, pp.1225--1228 (1999)

[8] Inácio, D., Inácio, S. Pina, J., Valtchev, S., Ventim-Neves, M., Martins, J., Rodrigues, A.L.: Conventional and HTS disc motor with pole variation control, International Conference on Power Engineering, Energy and Electrical Drives, 2009. POWERENG '09, Portugal, pp.513--518 (2009)

[9] Jung, H., Nakamura, T., Tanaka, N., Muta, I., Hoshino, T.: Characteristic analysis of hysteresis-type Bi-2223 bulk motor with the use of equivalent circuit, Physica C, vol. 405, p.p. 117--126 (2004) 